\title{
Pengembangan Aplikasi Mobile untuk Mempermudah Pencarian Informasi Rute Angkutan Kota Di Bandung
}

\author{
Priska Pricilia $^{* 1)}$ dan Johanna Renny Octavia ${ }^{2)}$ \\ ${ }^{1,2)}$ Program Studi Teknik Industri, Fakultas Teknologi Industri, Universitas Katolik Parahyangan, \\ Ciumbuleuit 94, Bandung, 40141, Indonesia
}

\begin{abstract}
In the fast globalization era, people need good public transportation facilities to easily carry out their daily activities. However, public transportation such as angkutan kota mostly is not preferred compared to other modes of public transportation because it is difficult to acquire necessary information regarding angkutan kota routes in one area. This research aims to develop a mobile application to enhance the process of acquiring information of angkutan kota routes in Bandung. Eight potential users of the developed application were involved as participants in the research, from the identification of user needs through interviews and usability testing, the selection of design concept, to the evaluation of prototype. Based on the thirteen identified user needs, we developed two alternative design concepts from which we chose one best concept to be developed further into a prototype. The evaluation of the prototype through usability testing showed that the developed mobile application has good usability with $73 \%$ of efficiency measure, 90\% of effectiveness measure, 78\% of learnability measure and System Usability Score (SUS) of 71,25.
\end{abstract}

Keywords: Angkutan Kota, Mobile Application, Route Information, Development, Usability Testing

\section{Pendahuluan}

Di era globalisasi ini, manusia butuh melakukan segala aktivitasnya dengan cepat. Aktivitas manusia pun tidak fokus di salah satu tempat saja, melainkan di beberapa tempat. Perpindahan aktivitas manusia ini tentunya perlu didukung oleh sarana transportasi yang baik. Transportasi pribadi merupakan transportasi yang paling cepat mengakomodasi perpindahan manusia, karena dapat menyesuaikan dengan kebutuhan pribadi manusia tersebut. Namun, tidak semua manusia memiliki transportasi pribadi, maka diperlukan transportasi umum yang cepat, murah, mudah, dan aman.

Transportasi umum merupakan solusi dari transportasi pribadi yang tidak dimiliki oleh setiap orang. Transportasi umum di zaman sekarang tidak hanya terbatas pada kereta, busway, bus DAMRI dan angkutan kota (yang selanjutnya disebut angkot). GOJEK maupun UBER merupakan sarana transportasi lainnya yaitu sarana transportasi pribadi yang berbasis aplikasi online. Taksi maupun ojek berbasis aplikasi online sangat digemari dewasa ini karena pemesanannya yang mudah yaitu tinggal diakses melalui aplikasi yang terdapat pada smartphone. Munculnya sarana transportasi berbasis aplikasi online membuat transportasi umumkurang digemari masyarakat. Hal ini disebabkan karena susahnya mendapatkan informasi rute dari transportasi umum. Sulitnya mendapatkan informasi mengenai rute dari angkutan umum membuat masyarakat malas untuk menggunakan transportasi umum.Namun, transportasi umum tidak begitu saja ditinggalkan oleh para penggunanya. Tarif yang jauh lebih murah daripada transportasi pribadi membuat transportasi umummasih banyak diburu masyarakat.

Sebenarnya sudah adaaplikasi untuk mencari rute angkutan kota di Bandung, yaitu aplikasi Rute Angkot Bandung dan KIRI Smart Public Transport. Namun, masih terdapat kekurangan pada kedua aplikasi tersebut berdasarkanreview di Play Store dan hasil wawancara awal. Oleh sebab itu, diperlukan suatu aplikasi yang dapat mempermudah pengguna untuk mencari informasi rute-rute yang dimiliki oleh transportasi umum. Tujuan penelitian ini untuk mengembangkan aplikasi mobile untuk mempermudah pencarian informasi rute angkutan kota di Bandung.

\footnotetext{
*Correspondance : ${ }^{\text {* }}$ priskapricilia@hotmail.com, ${ }^{2)}$ johanna@unpar.ac.id
} 


\section{Metode}

Desain interaksi menurut Preece, Sharp, dan Roger (2002) bertujuan untuk mendesain suatu produk yang interaktif untuk mendukung manusia dalam kehidupan dan aktivitas seharihari. Menurut Winograd (1997), desain interaksi merupakan desain ruang yang dirancang untuk komunikasi dan interaksi manusia. Metode yang digunakan untuk mengembangkan aplikasi mobile ini adalah pendekatan yang berdasarkan Interaction Design Lifecycle Model atau tahapan desain interaksi yang dapat dilihat pada Gambar 1. Menurut Preece et al. (2002), tahapan-tahapan dari desain interaksi adalah identifikasi kebutuhan dan penetapan kebutuhan, pengembangan desain alternatif, pembuatan prototipe, dan evaluasi.

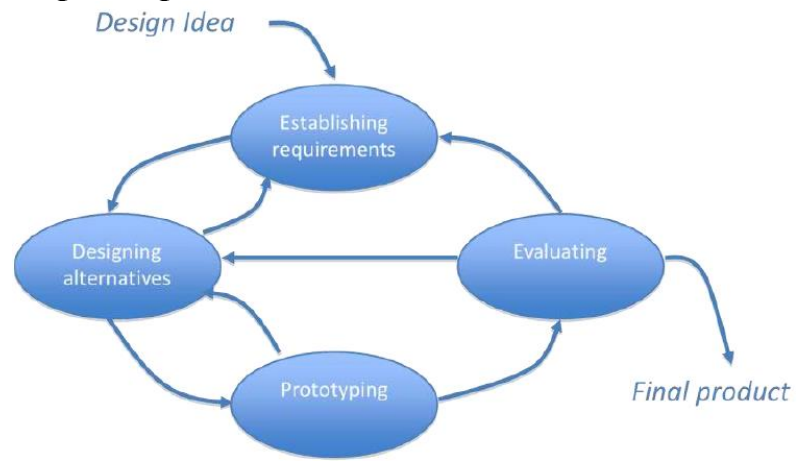

Gambar 1.Interaction Design Lifecycle Model

Tahap pengembangan aplikasi dimulai dengan menentukan kriteria responden. Responden dilibatkan untuk mendapatkan identifikasi kebutuhan. Delapan orang responden dilibatkan dalam proses identifikasi kebutuhan yang dilakukan dengan wawancara dan usability testing dari aplikasi yang sudah ada yaitu Rute Angkot Bandung dan KIRI Smart Public Transport. Responden yang dipilih untuk tahap identifikasi kebutuhan dan usability testing memiliki kriteria tertentu. Kriteria pertama adalah intensitas penggunaan angkutan kota yang dibagi menjadi dua yaitu yang sering memakai angkutan kota dan yang jarang maupun tidak pernah memakai angkutan kota. Responden yang tergolong sering menggunakan angkutan kota minimal seminggu tiga kali secara rutin dalam setiap aktivitasnya. Kriteria kedua adalah memiliki smartphone lebih dari enam bulan dan memiliki aplikasi minimal delapan buah aplikasi. Responden yang digunakan pada tahap wawancara dan usability testing juga merupakan responden yang sama untuk tahap pemilihan konsep desain dan evaluasi prototipe.

Pengembangan konsep desain dalam penelitian dilakukan dengan perancangan alternatif konsep berdasarkan identifikasi kebutuhan yang sudah didapatkan. Desain yang sudah dibuat selanjutnya dilakukan penilaian agar dapat dipilih desain terbaik untuk dibuat prototipe. Penilaian dilakukan dengan penilaian kualitatif yaitu dengan melihat kelebihan dan kekurangan dari alternatif yang ada. Selain itu, dilakukan juga dengan penilaian kuantitatif yaitu dengan memberi bobot pada masing-masing alternatif dan total bobot dari alternatif yang ada yaitu sebesar 100 . Penilaian juga dilakukan dengan melihat persentase pemenuhan kebutuhan dari kebutuhan yang sudah ditetapkan sebelumnya.

Perancangan prototipedilakukan berdasarkan konsep desain yang sudah terpilih. Prototipeyang dibuat merupakan high fidelity prototipe. Perancangan prototipetidak terpaku dari konsep desain terpilih namun juga menyertakan kekurangan yang dimiliki dari konsep desain terpilih agar prototipeyang dibuat dapat lebih baik lagi. Perancangan prototipe dibuat menggunakan software Justinmind (https://www.justinmind.com/).

Evaluasi prototipedilakukandengan usability testing berdasarkan task scenario yang sudah dibuat (Rubin dan Chisnell, 2008). Pengukuran yang dilakukan dalam melakukan evaluasi prototipe adalah pengukuran kuantitatif dan kualitatif. Pengukuran kuantitatif yang dilakukan 
antara lain waktu penyelesaian setiap task,jumlah bantuan yang diberikan dalam setiap task, dan jumlah responden yang menyelesaikan task dengan sukses, yaitu tanpa error dan tanpa bantuan.Pengukuran kualitatif yang dilakukan yaitu untuk mengukur tipe error dan komentar dari responden.

Pengukuran kualitatif dan kuantitatif berguna untuk mengukur kriteria usability. Kriteria usability yang digunakan untuk evaluasi prototipe yaitu efficiency dengan parameter persentase responden mengerjakan di bawah waktu standar (berdasarkan data waktu penyelesaiantask), effectiveness dengan parameter persentasetask sukses, tanpa error (berdasarkan data jumlah responden sukses tiap task), dan learnability dengan parameter persentasetask sukses tanpa bantuan (berdasarkan data jumlah yang harus dibantu tiap task).Selain itu, pengukuran kuantitatif dan kualitatif juga berguna untuk mengetahui usability problem. Evaluasi juga dilakukan dengan skor System Usability Scale (SUS) untuk mengukur usability dari prototipeyang dibuat (Brooke, 2013). Berdasarkan tipe error yang diukur, yaitu dengan melihat kesalahan yang dilakukan tiap responden, selanjutnya akan diketahui usability problem dari setiap kesalahan yang ada. Usability problem yang ada selanjutnya akan diberikan usulan perbaikan.

\section{Hasil dan Pembahasan}

Hasil dan pembahasan didapatkan dari pengembangan aplikasi yang dilakukan. Hasil dan pembahasan dimulai dengan identifikasi kebutuhan, pengembangan konsep desain, perancangan prototipe, evaluasi prototipe, serta usulan perbaikan.

\section{Identifikasi Kebutuhan}

Identifikasi kebutuhan dilakukan untuk mengetahui kebutuhan-kebutuhan dari user mengenai aplikasi yang akan dikembangkan. Identifikasi kebutuhan dilakukan dengan wawancara dan usability testing dari aplikasi sejenis. Proses identifikasi kebutuhan untuk wawancara dilakukan dengan menanyakan lima pertanyaan kepada responden yaitu :

1. Bagaimana cara Anda menemukan informasi rute angkutan kota di Bandung?

2. Apa saja kendala yang dihadapi untuk mengetahui pencarian informasi rute angkutan kota di Bandung?

3. Apa saja yang perlu diketahui dari pencarian informasi angkutan kota di Bandung?

4. Bagaimana pendapat Anda mengenai aplikasi mobile untuk mempermudah pencarian informasi rute angkutan kota di Bandung?

5. Fitur-fitur apa saja yang dibutuhkan dari aplikasi mobile untuk mempermudah pencarian informasi rute angkutan kota di Bandung?

Hasil wawancara dari salah satu responden yang ada dapat dilihat pada Tabel 1.

Tabel 1. Hasil Wawancara Responden 2

\begin{tabular}{|c|c|}
\hline Umur & 20 \\
\hline Pekerjaan & Mahasiswa \\
\hline Intensitas Penggunaan Angkutan Kota & $5 \mathrm{x}$ seminggu \\
\hline Lama Memiliki Smartphone & 3 tahun \\
\hline Jumlah Aplikasi yang Sering Digunakan & $\begin{array}{l}8 \text { (gojek, uber, BBM, whatsapp, instagram, line, path, } \\
\text { snapchat) }\end{array}$ \\
\hline \multicolumn{2}{|r|}{ Hasil Wawancara } \\
\hline Pertanyaan & Jawaban \\
\hline $\begin{array}{l}\text { Cara menemukan informasi rute angkutan } \\
\text { kota di Bandung }\end{array}$ & Bertanya pada orang sekitar, keluarga \\
\hline
\end{tabular}




\begin{tabular}{|l|l|}
\hline $\begin{array}{l}\text { Kendala yang dihadapi untuk mengetahui } \\
\text { pencarian informasi rute angkutan kota di } \\
\text { Bandung }\end{array}$ & $\begin{array}{l}\text { Banyak jalan di Bandung yang satu arah, banyak harus } \\
\text { ganti-ganti angkot jadi bingung karena harus naik } \\
\text { angkot berulang-ulang; naik angkot tidak tahu } \\
\text { berhentinya atau ujungnya sampai mana (contoh : naik } \\
\text { angkot Ciumbuleuit tapi gak tahu berhentinya sampai } \\
\text { mana, sampai tempat yang akan dituju atau tidak) }\end{array}$ \\
\hline $\begin{array}{l}\text { Hal-hal yang perlu diketahui dari } \\
\text { pencarian informasi angkutan kota di } \\
\text { Bandung }\end{array}$ & $\begin{array}{l}\text { Rute yang dilewati setiap angkot yang ada di Bandung; } \\
\text { tarif; waktu tempuh untuk mencapai suatu tujuan }\end{array}$ \\
\hline $\begin{array}{l}\text { Pendapat mengenai aplikasi mobile untuk } \\
\text { mempermudah pencarian informasi rute } \\
\text { angkutan kota di Bandung }\end{array}$ & $\begin{array}{l}\text { Setuju, bisa mempermudah pencarian apalagi untuk } \\
\text { orang baru yang tidak tahu jalan }\end{array}$ \\
\hline $\begin{array}{l}\text { Fitur-fitur yang dibutuhkan dari aplikasi } \\
\text { mobile untuk mempermudah pencarian } \\
\text { informasi rute angkutan kota di Bandung }\end{array}$ & Waktu tempuh; gambar angkotnya; estimasi biaya \\
\hline
\end{tabular}

Dari hasil wawancara, selanjutnya dilakukan interpretasi kebutuhan yang hasilnya dapat dilihat pada Tabel 2.

Tabel 2. Interpretasi Kebutuhan Berdasarkan Hasil Wawancara Responden 2

\begin{tabular}{|l|l|}
\hline \multicolumn{1}{|c|}{ Pernyataan } & \multicolumn{1}{c|}{ Interpretasi Kebutuhan } \\
\hline Rute yang dilewati angkot yang ada di Bandung & $\begin{array}{l}\text { Aplikasi memiliki informasi rute angkot } \\
\text { yang jelas }\end{array}$ \\
\cline { 1 - 1 } Terdapat gambar angkot agar tidak salah naik & \multirow{2}{*}{ Aplikasi memiliki informasi tarif } \\
\cline { 1 - 1 } Informasi tarif dari angkot yang digunakan & \multirow{2}{*}{ Aplikasi memiliki informasi waktu tempuh } \\
\cline { 1 - 2 } Estimasi biaya dari angkot yang digunakan & $\begin{array}{l}\text { Waktu tempuh untuk mencapai suatu tujuan } \\
\text { tertentu }\end{array}$ \\
\hline
\end{tabular}

Identifikasi kebutuhan untuk usability testing dilakukan dengan aplikasi yang sudah ada yaitu aplikasi Rute Angkot Bandung dan KIRI Smart Public Transport. Task yang diberikan untuk mendapatkan kebutuhan berdasarkan usability testingdapat dilihat pada Tabel 3.

Tabel 3.TaskUsability Testing

\begin{tabular}{|c|l|}
\hline Task & \multicolumn{1}{c|}{ Deskripsi } \\
\hline \multirow{2}{*}{1} & Mencari rute dari The Harvest Dago menuju UNPAR \\
\cline { 2 - 2 } & $\begin{array}{l}\text { Lokasi awal tidak ditentukan berdasarkan GPS, namun diketik secara manual. (dengan GPS } \\
\text { dalam keadaan tidak menyala) }\end{array}$ \\
\hline \multirow{2}{*}{2} & Mencari rute dari The Harvest Dago menuju UNPAR \\
\cline { 2 - 2 } & $\begin{array}{l}\text { Lokasi awal ditentukan berdasarkan lokasi saat ini atau sekarang (dengan GPS dalam keadaan } \\
\text { menyala) }\end{array}$ \\
\hline
\end{tabular}

Hasil usability testing dari salah satu responden dapat dilihat pada Tabel 4.

Tabel 4. Hasil Usability Testing Responden 2

\begin{tabular}{|l|l|l|}
\hline & \multicolumn{1}{|c|}{ Rute Angkot Bandung } & \multicolumn{1}{c|}{ KIRI Smart Public Transport } \\
\hline Kendala & Bingung memasukkan lokasi asal & \multicolumn{1}{c|}{-} \\
\hline Pendapat & $\begin{array}{l}\text { Tampilannya tulisan saja jadi bingung } \\
\text { angkot mana yang harus digunakan }\end{array}$ & $\begin{array}{l}\text { Sudah bagus ada gambar angkotnya, ada } \\
\text { map; bingung membaca step-step nya, } \\
\text { harus memencet apa antar step }\end{array}$ \\
\hline Tambahan Fitur & Estimasi biaya; waktu tempuh \\
\hline
\end{tabular}


Dari hasil usability testing, selanjutnya dilakukan interpretasi kebutuhan yang dapat dilihat pada Tabel 5.

Tabel 5. Interpretasi Kebutuhan Berdasarkan Hasil Usability Testing Responden 2

\begin{tabular}{|l|l|}
\hline \multicolumn{1}{|c|}{ Kendala atau Pendapat } & \multicolumn{1}{|c|}{ Interpretasi Kebutuhan } \\
\hline Bingung memasukkan lokasi asal & $\begin{array}{l}\text { Aplikasi memiliki tampilan yang jelas } \\
\text { untuk meng-input lokasi }\end{array}$ \\
\hline $\begin{array}{l}\text { Tampilannya tulisan saja jadi bingung angkot mana yang } \\
\text { harus digunakan }\end{array}$ & Aplikasi mudah digunakan \\
\cline { 1 - 2 } $\begin{array}{l}\text { Bingung membaca step-step nya, harus memencet apa } \\
\text { antar step }\end{array}$ & $\begin{array}{l}\text { Aplikasi memiliki peta yang dapat } \\
\text { menunjukkan rute yang dituju }\end{array}$ \\
\hline Sudah bagus ada gambar angkotnya, ada map & \\
\hline
\end{tabular}

Berdasarkan wawancara dan usability testing dari aplikasi yang sudah ada, didapatkan tiga belas kebutuhan yang dapat dilihat pada Tabel 6 .

Tabel 6. Kebutuhan yang Teridentifikasi

\begin{tabular}{|c|c|c|}
\hline No & Interpretasi Kebutuhan & $\begin{array}{c}\text { Frekuensi } \\
\text { Kemunculan } \\
\text { Kebutuhan }\end{array}$ \\
\hline 1 & Aplikasi memiliki informasi rute angkot yang jelas & 29 \\
\hline 2 & Aplikasi memiliki tampilan yang jelas untuk meng-input lokasi & 12 \\
\hline 3 & Aplikasi memiliki informasi tarif & 9 \\
\hline 4 & Aplikasi memiliki informasi yang jelas & 6 \\
\hline 5 & Aplikasi mudah digunakan & 6 \\
\hline 6 & Aplikasi memiliki peta yang dapat menunjukkan rute yang dituju & 5 \\
\hline 7 & Aplikasi memiliki tampilan yang menarik & 3 \\
\hline 8 & Aplikasi memiliki informasi waktu operasional angkot & 3 \\
\hline 9 & Aplikasi memiliki informasi waktu tempuh & 3 \\
\hline 10 & Aplikasi menggunakan bahasa Indonesia & 1 \\
\hline 11 & Aplikasi memiliki informasi alternatif angkot & 1 \\
\hline 12 & Aplikasi memiliki informasi keberadaan angkot & 1 \\
\hline 13 & Aplikasi memiliki informasi supir angkot & 1 \\
\hline
\end{tabular}

\section{Pengembangan Konsep Desain}

Pengembangan konsep desain dimulai dengan perancangan prototipeberdasarkan kebutuhan yang teridentifikasi pada Tabel 6.Konsep desain yang dibuat terdiri dari dua buah alternatif yang dirancang dengan mempertimbangkan konsep dari aplikasi yang sudah ada yaitu Rute Angkot Bandung dan KIRI Smart Public Transport.Gambar 2 merupakan tampilan dari alternatif konsep pertama.
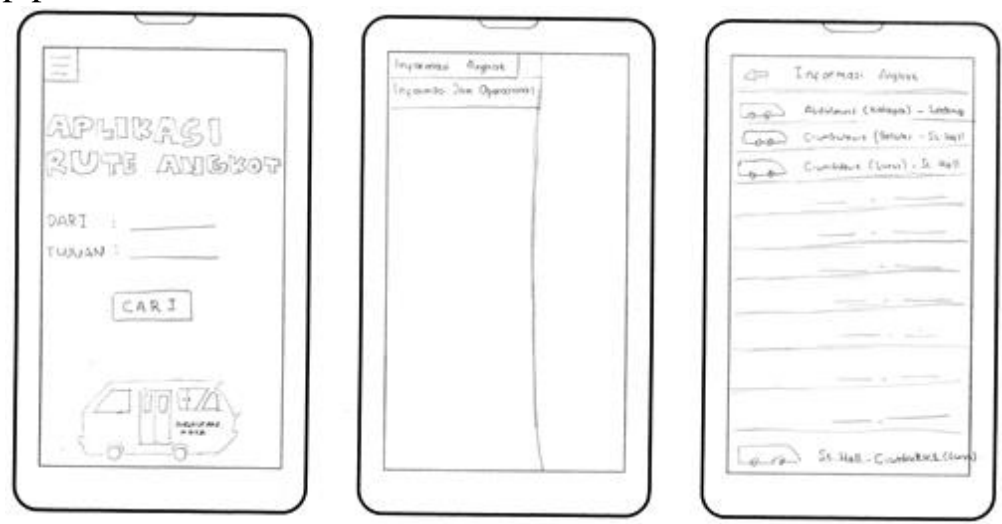

Gambar 2. Alternatif Konsep 1 
Tampilan alternatif konsep kedua yang dibuat dapat dilihat dalam Gambar 3.
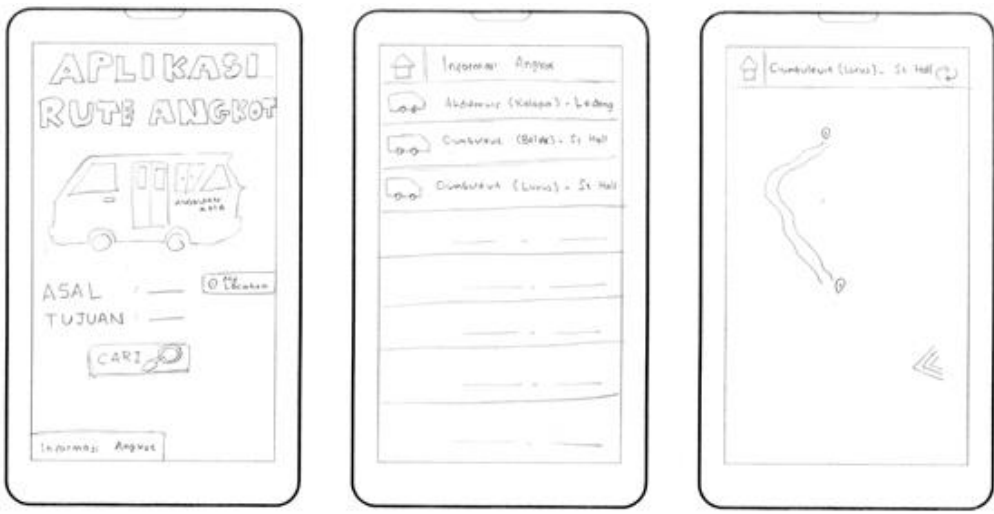

Gambar 3. Alternatif Konsep 2

Alternatif konsep yang sudah dibuat selanjutnya diberikan penilaian kuantitatif yaitu dengan meminta responden untuk membagikan skor 100 kepada kedua alternatif. Berdasarkan jawaban dari delapan responden, total skor dari alternatif konsep 1 sebesar 255 dan alternatif konsep 2 sebesar 545.Selain penilaian kuantitatif, dilakukan juga penilaian kualitatif pada kedua alternatifkonsep yang dapat dilihat pada Tabel 7.

Tabel 7.PenilaianKualitatif Terhadap Konsep

\begin{tabular}{|c|l|l|}
\hline Alternatif & \multicolumn{1}{|c|}{ Kelebihan } & \multicolumn{1}{c|}{ Kekurangan } \\
\hline \multirow{2}{*}{1} & Lebih simpel menggunakan aplikasinya & $\begin{array}{l}\text { Ribet karena harus bolak balik untuk } \\
\text { mengetahui informasi angkot dan jam } \\
\text { operasional angkot }\end{array}$ \\
\cline { 2 - 3 } 2 & Sudah baik, karena ada alternatif rute & Tombol >> kurang jelas untuk apa \\
\cline { 2 - 3 } 2 & $\begin{array}{l}\text { Lebih simpel karena informasi rute dan } \\
\text { jam operasional digabung }\end{array}$ & $\begin{array}{l}\text { Seharusnya tau keadaan jalan macet atau } \\
\text { tidak agar bisa memilih rute alternatif }\end{array}$ \\
\hline
\end{tabular}

Berdasarkan kebutuhan yang teridentifikasi, kedua alternatif konsep ditinjau sejauh mana tiap konsep berhasil memenuhi kebutuhan yang hasilnya dapat dilihat pada Tabel8.

Tabel 8. Pemenuhan Kebutuhan

\begin{tabular}{|l|l|c|c|}
\hline No & \multicolumn{1}{|c|}{ Interpretasi Kebutuhan } & Alternatif 1 & Alternatif 2 \\
\hline 1 & Aplikasi memiliki informasi rute angkot yang jelas & $\checkmark$ & $\checkmark$ \\
\hline 2 & $\begin{array}{l}\text { Aplikasi memiliki tampilan yang jelas untuk meng-input } \\
\text { lokasi }\end{array}$ & - & $\checkmark$ \\
\hline 3 & Aplikasi memiliki informasi tarif & - & $\checkmark$ \\
\hline 4 & Aplikasi memiliki informasi yang jelas & $\checkmark$ & $\checkmark$ \\
\hline 5 & Aplikasi mudah digunakan & - & $\checkmark$ \\
\hline 6 & $\begin{array}{l}\text { Aplikasi memiliki peta yang dapat menunjukkan rute yang } \\
\text { dituju }\end{array}$ & - & $\checkmark$ \\
\hline 7 & Aplikasi memiliki tampilan yang menarik & $\checkmark$ & $\checkmark$ \\
\hline 8 & Aplikasi memiliki informasi waktu operasional angkot & $\checkmark$ & $\checkmark$ \\
\hline 9 & Aplikasi memiliki informasi waktu tempuh & $\checkmark$ & $\checkmark$ \\
\hline 10 & Aplikasi menggunakan bahasa Indonesia & $\checkmark$ & $\checkmark$ \\
\hline 11 & Aplikasi memiliki informasi alternatif angkot & - & $\checkmark$ \\
\hline 12 & Aplikasi memiliki informasi keberadaan angkot & - & - \\
\hline 13 & Aplikasi memiliki informasi supir angkot & - & - \\
\hline & & $69 \%$ & $85 \%$ \\
\hline
\end{tabular}


Jadi, berdasarkan penilaian kuantitatif dan kualitatif serta pemenuhan kebutuhan, dapat disimpulkan bahwa alternatif konsep 2 merupakan konsep terpilih yang selanjutnya akan dibuat prototipenya.

\section{PerancanganPrototipe}

Prototipe dibuat berdasarkan konsep terpilih berdasarkan alternatif konsep 2. Pembuatan prototipetidak murni berasal dari alternatif konsep 2 saja, namun juga mempertimbangkan penilaian kualitatif yang diberikan responden. Prototipedibuat menggunakan program Justinmind (https://www.justinmind.com/). Contoh prototipe yang sudah dibuat dapat dilihat pada Gambar 4.
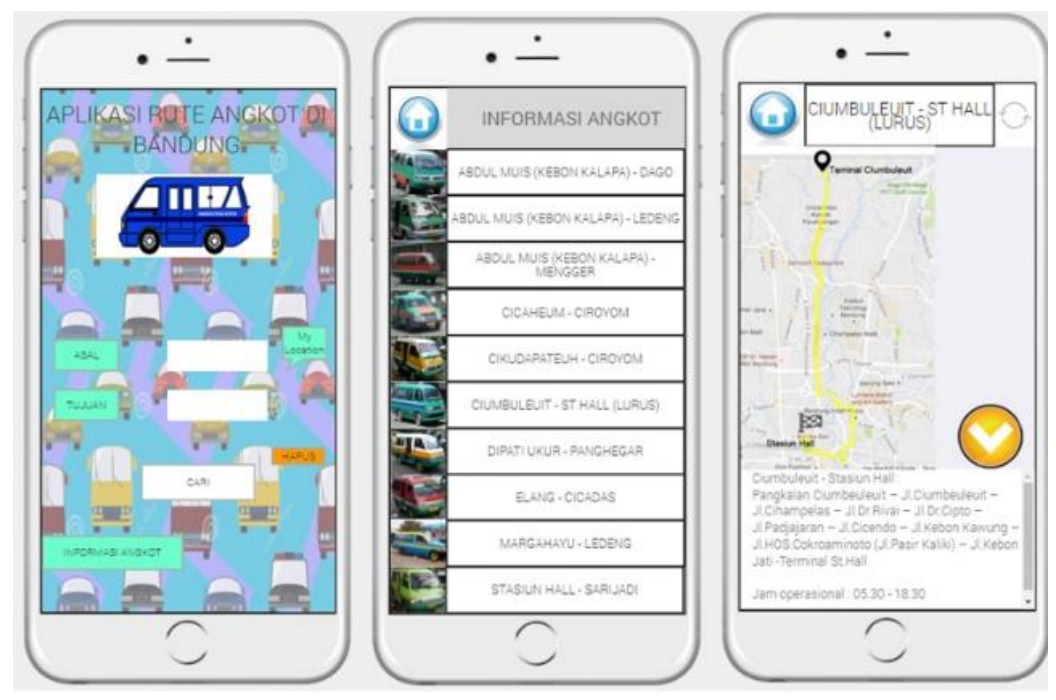

Gambar 4.Prototipe

\section{Evaluasi Prototipe}

Pengujian prototipeberguna untuk mengevaluasi prototipeyang sudah dibuat. Pengujian prototipe dilakukan dengan meminta responden untuk menyelesaikan lima tugas berdasarkan task scenario yang dapat dilihat pada Tabel 9.

Tabel 9.Task Scenario

\begin{tabular}{|c|c|}
\hline Task & Deskripsi \\
\hline 1 & $\begin{array}{l}\text { Mencari informasi rute yang dilewati dan jam operasional angkot Ciumbuleuit (Lurus) - St. } \\
\text { Hall }\end{array}$ \\
\hline 2 & $\begin{array}{l}\text { Mencari informasi rute yang dilewati dan jam operasional angkot St. Hall - Ciumbuleuit } \\
\text { (Lurus) }\end{array}$ \\
\hline \multirow{2}{*}{3} & $\begin{array}{l}\text { Mencari informasi rute angkot dari lokasi sekarang (Asumsi : lokasi saat ini yaitu UNPAR) } \\
\text { menuju BTC }\end{array}$ \\
\hline & $\begin{array}{l}\text { Menyebutkan angkot yang digunakan menuju BTC, tarif angkot, estimasi waktu, tarif total } \\
\text { serta arahan yang diberikan untuk berjalan kaki (jika ada) }\end{array}$ \\
\hline \multirow{2}{*}{4} & $\begin{array}{l}\text { Mencari informasi rute angkot dari lokasi sekarang (Asumsi : lokasi saat ini yaitu UNPAR) } \\
\text { menuju BTC dengan rute yang berbeda dari rute yang sebelumnya }\end{array}$ \\
\hline & $\begin{array}{l}\text { Menyebutkan angkot yang digunakan menuju BTC, tarif angkot, estimasi waktu, tarif total } \\
\text { serta arahan yang diberikan untuk berjalan kaki (jika ada) }\end{array}$ \\
\hline \multirow[b]{2}{*}{5} & Mencari informasi rute angkot dari Sabuga menuju Sushi Tei Flamboyant \\
\hline & $\begin{array}{l}\text { Menyebutkan angkot yang digunakan menuju Sushi Tei Flamboyant, tarif angkot, estimasi } \\
\text { waktu, tarif total serta arahan yang diberikan untuk berjalan kaki (jika ada) }\end{array}$ \\
\hline
\end{tabular}


Hasil evaluasi prototipediperoleh melalui pengukuran kuantitatif dan kualitatif untuk mengukur kirteria usability dan mengidentifikasiusability problem. Tabel 10 merupakan kriteria usability yang diukur.

Tabel 10. Kriteria Usability

\begin{tabular}{|c|l|l|}
\hline No & Kriteria & \multicolumn{1}{c|}{ Parameter } \\
\hline 1 & Efficiency & $\begin{array}{l}\text { Persentase responden mengerjakan di bawah waktu standar } \\
\text { (berdasarkan data waktu penyelesaiantask) }\end{array}$ \\
\hline 2 & Effectiveness & $\begin{array}{l}\text { Persentasetask sukses, tanpa } \text { error } \\
\text { (berdasarkan data jumlah responden sukses tiap task) }\end{array}$ \\
\hline 3 & Learnability & $\begin{array}{l}\text { Persentasetask sukses tanpa bantuan } \\
\text { (berdasarkan data jumlah yang harus dibantu tiap task) }\end{array}$ \\
\hline
\end{tabular}

Hasil perhitungan kriteria usability yang digunakan yaitu efficiency, effectiveness, dan learnability dapat dilihat pada Tabel 11.

Tabel 11.Perhitungan Kriteria Usability

\begin{tabular}{|l|c|c|c|c|c|c|}
\hline Parameter & Task 1 & Task 2 & Task 3 & Task 4 & Task 5 & Rata-rata \\
\hline Efficiency & $50 \%$ & $75 \%$ & $75 \%$ & $75 \%$ & $88 \%$ & $73 \%$ \\
\hline Effectiveness & $63 \%$ & $75 \%$ & $75 \%$ & $75 \%$ & $100 \%$ & $78 \%$ \\
\hline Learnability & $75 \%$ & $75 \%$ & $100 \%$ & $100 \%$ & $100 \%$ & $90 \%$ \\
\hline
\end{tabular}

Nilai skor SUS yang didapatkan adalah sebesar 71,25 dari 8 responden yang ada. Skoryang didapatkan termasuk kategori baik namun masih perlu dilakukan perbaikan. Dari hasil evaluasi didapatkan juga kesulitan maupun kesalahan responden yang dapat dijadikan dasar untuk mengidentifikasi usability problem yang dapat dilihat Tabel 12 .

Tabel 12.Usability Problem

\begin{tabular}{|l|l|l|}
\hline Task & \multicolumn{1}{|c|}{ Kesulitan / Kesalahan Responden } & \multicolumn{1}{c|}{ Usability Problem } \\
\hline 1 & $\begin{array}{l}\text { Salah pencet tombol, mengetik di kolom } \\
\text { asal dan tujuan }\end{array}$ & $\begin{array}{l}\text { Responden tidak mengetahui adanya fitur } \\
\text { informasi angkot }\end{array}$ \\
\hline \multirow{2}{*}{2} & $\begin{array}{l}\text { Salah pencet tombol, mengetik di kolom } \\
\text { asal dan tujuan }\end{array}$ & $\begin{array}{l}\text { Responden tidak mengetahui adanya fitur } \\
\text { informasi angkot }\end{array}$ \\
\cline { 2 - 3 } & Bolak-balik halaman informasi angkot & Responden tidak mengetahui adanya fitur reverse \\
\cline { 2 - 3 } 3 & Bingung harus memencet tombol apa & Responden tidak mengetahui adanya fitur reverse \\
\hline \multirow{3}{*}{3} & $\begin{array}{l}\text { My location diketik, seharusnya tinggal } \\
\text { klik }\end{array}$ & $\begin{array}{l}\text { Responden tidak mengetahui adanya fitur } \text { my } \\
\text { location }\end{array}$ \\
\cline { 2 - 3 } & $\begin{array}{l}\text { Salah pencet tombol, memencet } \\
\text { informasi angkot }\end{array}$ & $\begin{array}{l}\text { Responden terbiasa memencet informasi angkot, } \\
\text { padahal } \text { task yang sekarang berbeda yang sudah } \\
\text { dikerjakan sebelumnya }\end{array}$ \\
\hline \multirow{2}{*}{4} & $\begin{array}{l}\text { My location diketik, seharusnya tinggal } \\
\text { klik }\end{array}$ & $\begin{array}{l}\text { Responden tidak mengetahui adanya fitur } \text { my } \\
\text { location }\end{array}$ \\
\cline { 2 - 3 } & $\begin{array}{l}\text { Pencet tombol } \text { reverse } \text { untuk mencari } \\
\text { alternatif angkot }\end{array}$ & $\begin{array}{l}\text { Responden tidak mengetahui adanya fitur } \\
\text { alternatif angkot }\end{array}$ \\
\hline
\end{tabular}

\section{Usulan Perbaikan}

Usulan diberikan berdasarkan usability problem yang ada. Usulan perbaikan yang pertama adalah mengubah tampilan menu utama yang dapat dilihat pada Gambar 5 untuk mengatasi permasalahan pada task pertama yaitu responden tidak mengetahui adanya fitur informasi angkot. 


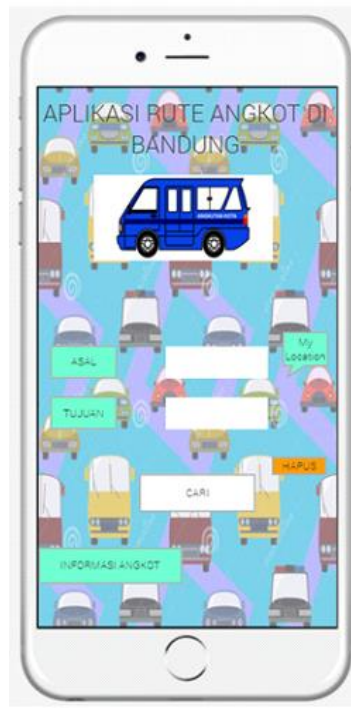

(a)

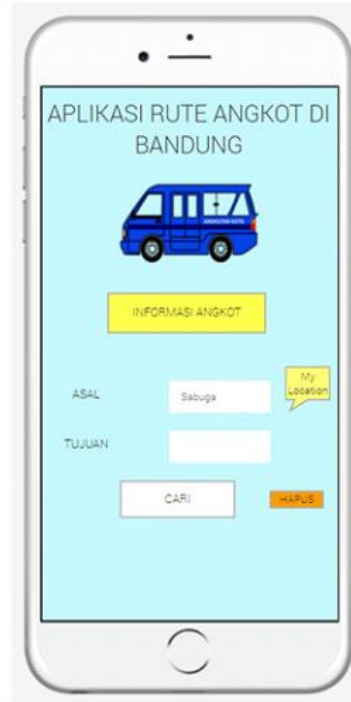

(b)

Gambar 5.Menu Utama: (a) Awal; (b) Usulan Perbaikan

Usulan perbaikan yang kedua adalah menambah kata reverse pada tombol reverse untuk mengatasi permasalahan pada task 2 yaituresponden tidak mengetahui adanya fitur reverseyang dapat dilihat pada Gambar 6.

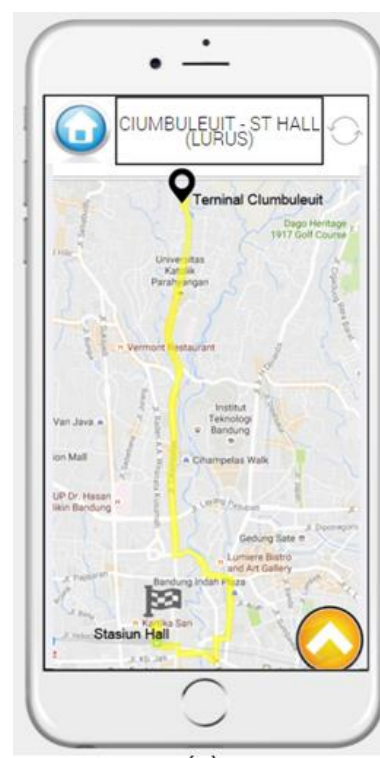

(a)

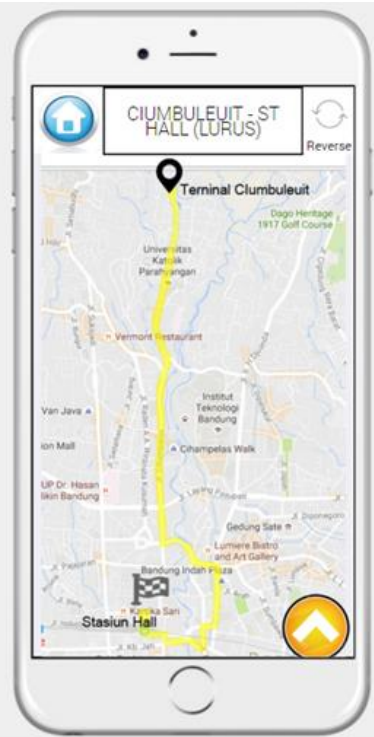

(b)

Gambar 6.Menu Informasi Angkot Ciumbuletuit (Lurus) - St. Hall:

(a) Awal; (b) Usulan Perbaikan

Usulan perbaikan yang ketiga adalah memperbesar kata-kata alternatif rute untuk mengatasi permasalahan pada task 4 yaitu responden tidak mengetahui adanya fitur alternatif angkotyang dapat dilihat pada Gambar 7. 


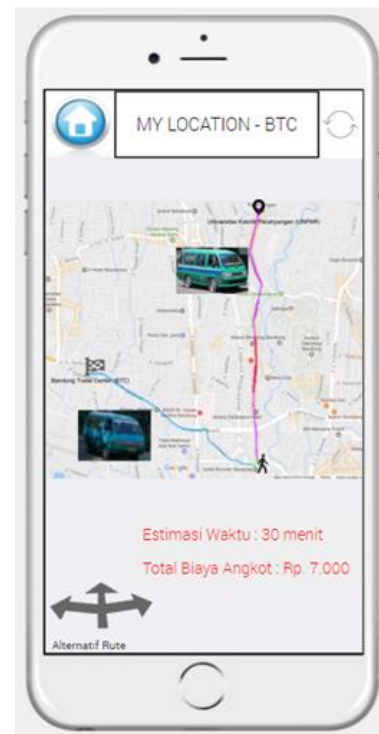

(a)

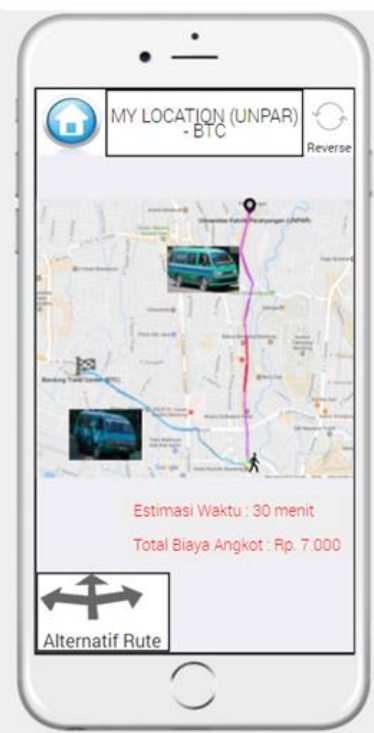

(b)

Gambar 7.Menu Informasi Rute My Location - BTC: (a) Awal; (b) Usulan Perbaikan

\section{Simpulan}

Fitur-fitur yang dibutuhkan pada aplikasi mobile untuk mempermudah pencarian informasi rute angkutan kota Bandung yang akan dikembangkan didapatkan berdasarkan identifikasi kebutuhan melalui wawancara dan usability testing. Proses identifikasi kebutuhan menghasilkan tiga belas kebutuhan yang perlu dipenuhi dalam rancangan aplikasi.Evaluasi dari prototipe aplikasi yang dikembangkan menghasilkan bahwa prototipe telah mencapai nilai efficiency,effectiveness, dan learnability dengan rata-rata yaitu 73\%, 78\%, dan 90\%.Selain itu, hasil evaluasi menunjukkan perolehan skor SUS sebesar 71,25 yang mengindikasikan bahwa prototipe yang dibuat sudah baik walaupun masih perlu perbaikan lebih lanjut.Usulan perbaikan meliputi usulan untuk mengubah letak informasi lokasi dan mengganti background, memberi tulisan dibawah simbol reverse, dan memperbesar tulisan alternatif rute.

\section{Daftar Pustaka}

Brooke, J. (2013). SUS: A retrospective.Journal of Usability Studies, Vol. 8, No. 2, pp. 29-40.

Preece, J., Sharp, H., dan Roger, Y. (2002).Interaction Design: Beyond Human-Computer Interaction. ${ }^{\text {st }}$ Edition. New York: Wiley Publishing, Inc.

Rubin, J. dan Chisnell, D. (2008). Handbook of Usability Testing: How to Plan, Design and Conduct Effective Tests. $2^{\text {nd }}$ Edition. Indianapolis: John Wiley\&Sons.

Winograd, T. (1997).From computing machinery to interaction design. In P. Denning and R. Metcalfe (eds.) BeyondCalculation: the Next Fifty Years of Computing. New York: Springer-Verlag. 